\title{
Viewpoints
}

\section{Bangladesh striving against double burden: Dengue outbreak surges amid COVID-19 pandemic}

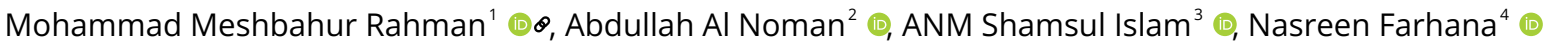 \\ 1 Department of Basic Science, World University of Bangladesh, Dhaka-1230, Bangladesh; Biomedical Research Foundation, Dhaka-1230, Bangladesh, \\ 2 Bioscience Academy Bangladesh, Bangladesh, ${ }^{3}$ Department of Public Health \& Hospital Administration, National Institute of Preventive \& Social \\ Medicine (NIPSOM), Mohakhali, Dhaka-1212, Bangladesh, 4 Department of Microbiology and Mycology, National Institute of Preventive \& Social \\ Medicine (NIPSOM), Mohakhali, Dhaka-1212, Bangladesh \\ Keywords: Dengue, COVD-19, Double Burden, Bangladesh \\ https://doi.org/10.52872/001c.29657
}

\section{Journal of Global Health Economics and Policy}

Vol. 1, 2021

\begin{abstract}
As one of the least developed countries of South Asia, Bangladesh continues experiencing a surge in the number of patients with dengue hemorrhagic fever (DHF), while struggling with the ongoing COVID-19 pandemic. The number of infected patients and deaths due to COVID-19 had risen rapidly since the beginning of July 2021 and broken all the previous records. The total number of dengue cases was also the highest in July. Now, the country is facing an unprecedented challenge of tackling a co-epidemic. Impoverished health infrastructure, ineffective intervention schemes against the disease and lack of awareness has made the country vulnerable to a risk of co-epidemic. Therefore, government and local authorities should take immediate actions, including capacity-building programs for both COVID-19 and dengue, while community engagement campaigns focusing on the destruction of breeding sources of Aedes mosquitoes can play a key role in reducing the effect of dengue at an early stage.
\end{abstract}

Bangladesh is facing the unprecedented challenge of tackling a double burden of disease- dengue outbreak surges amid the peak of the COVID-19 pandemic. The sharp rise in dengue cases is threatening Bangladesh's under-resourced healthcare system, striving against the country's third wave of COVID-19. South Asian countries such as India, Sri Lanka, and Myanmar are highly vulnerable to this tropical disease due to poor health infrastructure and effective intervention schemes against this hemorrhagic fevercausing virus. ${ }^{1}$ Bangladesh, a South Asian country, is also susceptible to the dengue virus. Though the virus first emerged in the year 2000 in the country, its greatest disaster had occurred in 2019.

The severity of COVID-19 infection had risen rapidly since the beginning of July 2021 and broken all the previous records concerning both infected cases and deaths. ${ }^{2}$ The spurt in cases was largely due to the newly emerged and highly infectious delta variant from India, first recorded in Bangladesh on May 8, 2021. ${ }^{3}$ From January 1 to May 8, 2021, the total number of SARS-CoV-2 infected patients in Bangladesh experienced to 213,617 , whereas this number surged to $4,77,357$ (over $123 \%$ increase) after detecting the delta variant and $78 \%$ of the total sample tested in June contained this variant. ${ }^{2,3}$ In this period, there was a fluctuation, but the number of infections had been rising rapidly. The month of July 2021 seemed to be the most menacing regarding COVID-19 when 336,226 cases and 6,039 deaths occurred, which was the highest for any month in Bangladesh (Figure 1, panel B and panel D).

Since the monsoon rain commenced in early July, dengue had joined the COVID-19 pandemic to batter the under- resourced healthcare. The month saw the spurt of dengue with 2,287 cases (Figure 1, Panel A and panel C), which was over a $514 \%$ increase in the cumulative number of dengue cases from previous months of this year. 4,5 The country was concerned with handling the COVID-19. Therefore, preventive measures to contain dengue were not maintained strictly, which contributed to this rapid rise. It is thought that dengue cases were particularly high this year because it followed a wave pattern whereby cases increased every alternate year - the last time being in $2019 .{ }^{6}$ The rise persisted in August and continued to add burdens to the health system, with over 200 cases every day. In the first week, the number of infected patients was 1,661, more than a $53 \%$ increase from the previous week (Figure 1). The actual number may be higher than official data because most hospitals were grappling with coronavirus caseload and underreporting of dengue could have occurred.

One of the alarming concerns for this year is that all dengue patients were infected by DENV-3, which was found to be the most virulent type among Southeast Asian patients. ${ }^{7}$ The prevalence of DENV-3 caused the largest dengue epidemic in Bangladesh in 2019, when 101,354 patients had infected mostly by this serotype. ${ }^{8}$ Fragile health infrastructure and insufficient preparedness against an outbreak caused massive health and economic loss in that year. Another concern was the similarities between symptoms of COVID-19 and dengue, particularly within the first few hours from symptoms onset. ${ }^{9}$ Hence, it was difficult to diagnose the actual cause in the first place and many patients became perplexed after getting SARS-CoV-2 negative results but no sign of lessening their symptoms. This con- 

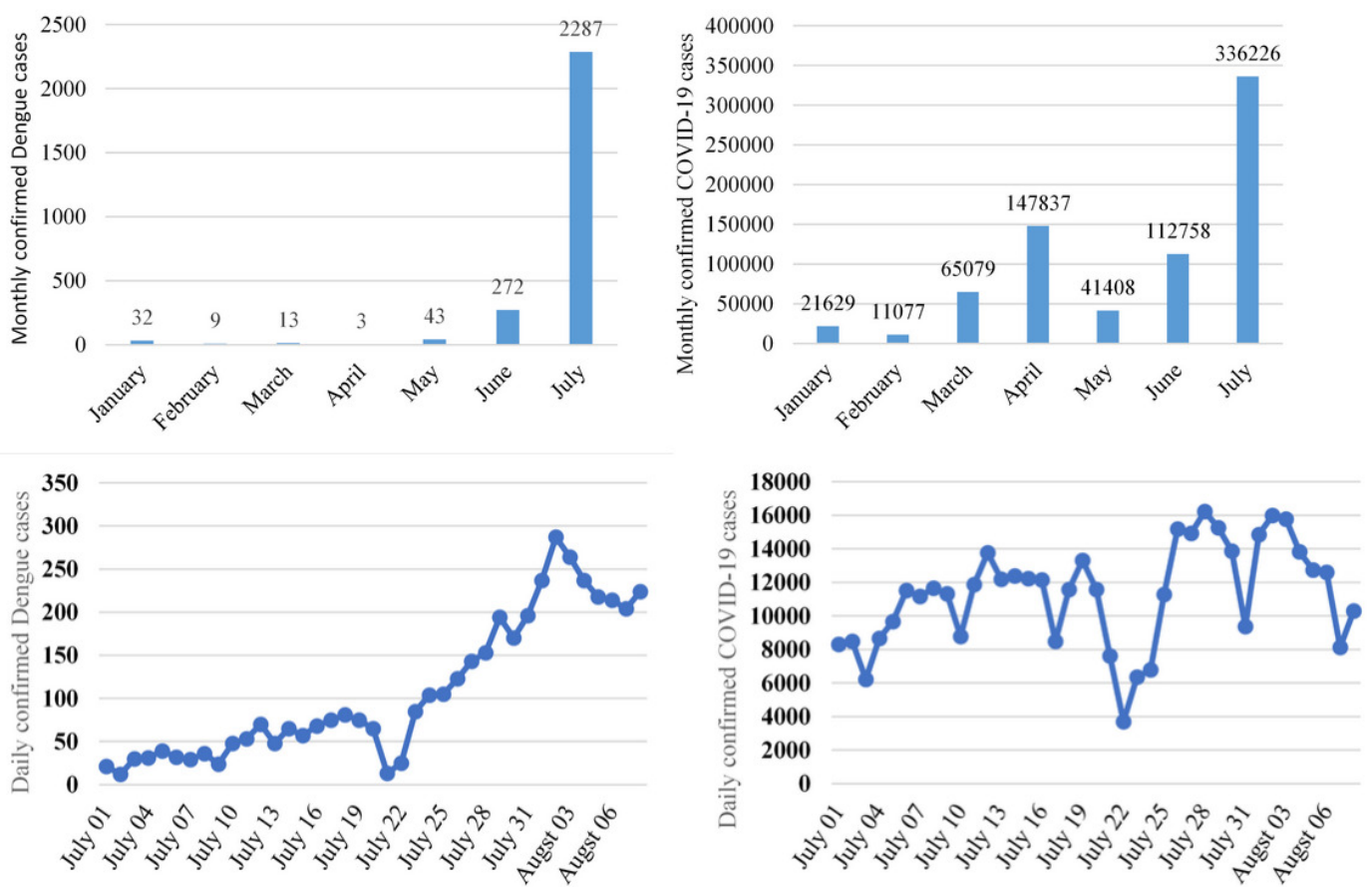

\section{Figure 1. Monthly confirmed cases}

(Figure 1, panel A) Dengue, (Figure 1, panel B) COVID-19. Daily confirmed cases (July and 01-08 August 2021) (Figure 1, panel C) Dengue, (Figure 1, panel D) COVID-19. Both COVID-19 and dengue cases were reported less from 20-23 July due to Eid-ul-Adha vacation and most hospitals were absent to report the data. [Figure 1 was generated on COVID-19 and dengue data obtained from the websites of the Institute of Epidemiology, Disease Control and Research (IEDCR), Directorate General of Health Services (DGHS), daily COVID-19 and dengue updates by electronic media.]

founding situation affected the mental well-being of patients, as well as financial loss due to unnecessary testing. ${ }^{6}$ Although government hospitals provide dengue testing free of cost, these are crowded with COVID-19 patients. Consequently, people with low income were facing the gravest repercussions of the emergence of these co-infections.

The government and local authorities started dengue eradication programs after the virus spread, and they have been doing this every year. Consequently, they have to rely on the climate, seasonal onset and trend of viral spread. Hence, if the virus surges as it did in 2019, the country will not be able to tackle the repercussions. Now, it is more of an individual's responsibility than the government.

A threat to the healthcare system of Bangladesh in outbreak preparedness is the shortage of healthcare professionals. The country hardly meets the WHO recommended 10 physicians per 10,000 population and cumulatively 44.5 healthcare professionals including doctors, nurses and midwives per 10,000 population. ${ }^{10}$ The doctor-population ratio in Bangladesh is 6.4:10,000, while there are 3.9 nurses and midwives per 10,000 population. ${ }^{11}$ Besides, a significant number of healthcare professionals lack the skills required to tackle an outbreak, ${ }^{12,13}$ let alone two, which has reflected by the concurrent rise of both COVID-19 and dengue cases. Another worry has the high number of slum dwellers, mainly in the capital city, where approximately 1.1 million people live in slums. ${ }^{14}$ They did not maintain hygiene practices due to living in a congested area and having a water shortage. Moreover, there is only one bathroom for every 10 to 16 families. ${ }^{15}$ These unfavourable conditions and their lack of proper knowledge made them a vulnerable popu- lation to the dengue virus. Therefore, dengue has posed a further challenge that needs more attention and proper case management schemes to prevent the chance of co-epidemics.

The scarcity of healthcare facilities, impoverished health infrastructures and inadvertency of people towards hygiene and preventive practices has made the country vulnerable to co-infections alongside COVID-19. If dengue cases rise similarly to COVID-19, it might cause one of the biggest catastrophes in the history of Bangladesh. Therefore, the country needs immediate actions such as capacity-building programs with individual coordination teams for both COVID-19 and dengue, and a massive vaccination effort against SARS-CoV-2. ${ }^{16}$ Furthermore, to prevent the dengue outbreak, campaigns focusing on the destruction of breeding sources of Aedes mosquitoes are mandatory, while community engagement programs can play a key role in reducing the effect at an early stage. ${ }^{17}$ Above all, active monitoring systems and comprehensive disease surveillance, supplemented by the raising awareness may lower the chance of wider co-epidemics.

\section{ACKNOWLEDGEMENTS}

We want to acknowledge Saiful Islam and Sharif Khiam Ahmed Eon for their help in collecting data and photographs. 


\section{FUNDING}

The authors received no funding for this study.

\section{AUTHOR'S CONTRIBUTION}

MMR was involved in the conception and design of the work, data acquisition, analysis, interpretation and drafting of the work. AAN was involved in data acquisition, analysis, interpretation and drafting of the work. SI was involved in data acquisition and drafting of the work. ANMSI and NF were involved in the drafting of the work. All authors read the manuscript for important intellectual context and approved the submission.

\section{COMPETING INTERESTS}

The authors completed the ICMJE Unified Competing In- terest form (available upon request from the corresponding author), and declare no conflicts of interest.

\section{ETHICS APPROVAL}

Not required.

\section{CORRESPONDENCE}

Mohammad Meshbahur Rahman, Lecturer, World University of Bangladesh, Dhaka-1230, Bangladesh, Phone +8801751509801; meshbah037@gmail.com

Submitted: October 21, 2021 CET, Accepted: October 25, 2021

CET 


\section{REFERENCES}

1. Dengue in the South-East Asia. https://www.who.in t/southeastasia/health-topics/dengue-and-severe-de ngue. Accessed August 15, 2021.

2. Institute of Epidemiology, Disease Control and Research (IEDCR. http://old.iedcr.gov.bd/. Accessed August 8, 2021.

3. IEDCR: $78 \%$ Covid cases in June caused by Delta variant. Dhaka Tribune. https://www.dhakatribune.co $\mathrm{m} /$ health/coronavirus/2021/07/04/iedcr-delta-varian t-dominant-in-bangladesh. Accessed August 2, 2021.

4. Dengue situation deteriorating. Daily Sun. http s://www.daily-sun.com/post/566804/Dengue-situatio n-deteriorating. Accessed August 1, 2021.

5. Alarming Dengue surge: 196 more hospitalised in 24 hrs. United News of Bangladesh. https://unb.com.b d/category/Bangladesh/alarming-dengue-surge-19 6-more-hospitalised-in-24-hrs/76396. Accessed August 1, 2021.

6. Double blow: Bangladesh battles dengue outbreak amid COVID crisis. Aljazeera. https://www.aljazeera.c om/news/2021/7/30/bangladesh-dengue-outbreak-co vid-crisis. Accessed August 1, 2021.

7. Soo K-M, Khalid B, Ching S-M, Chee H-Y. MetaAnalysis of Dengue Severity during Infection by Different Dengue Virus Serotypes in Primary and Secondary Infections. PLOS ONE. 2016;11(5):e0154760. doi:10.1371/journal.pone.0154 $\underline{760}$

8. Ahsan A, Haider N, Kock R, Benfield C. Possible Drivers of the 2019 Dengue Outbreak in Bangladesh: The Need for a Robust Community-Level Surveillance System. J Med Entomol. 2020;58:37-39. doi:10.1093/j me/tjaa150

9. Joubert A, Andry F, Bertolotti A, et al. Distinguishing non severe cases of dengue from COVID-19 in the context of co-epidemics: A cohort study in a SARS-CoV-2 testing center on Reunion island. PLoS Negl Trop Dis. 2021;15(4):e0008879. do i:10.1371/journal.pntd.0008879
10. Karan A, Negandhi H, Hussain S, et al. Size, composition and distribution of health workforce in India: Why, and where to invest? Hum Resour Health. 2021;19(1):1-14. doi:10.1186/s12960-021-00575-2

11. World Health Organization. Health Workforce Requirements for Universal Health Coverage and the Sustainable Development Goals. (Human Resources for Health Observer, 17). World Health Organization; 2016. https://apps.who.int/iris/handle/10665/250330.

12. Ahammed T, Anjum A, Rahman MM, Haider N, Kock R, Uddin MJ. Estimation of novel coronavirus (COVID - 19) reproduction number and case fatality rate: A systematic review and meta - analysis. Health Sci Rep. 2021;4(2):e274. doi:10.1002/hsr2.274

13. Haque MF, Rahman MM, Alif SM, et al. Estimation and prediction of doubling time for COVID-19 epidemic in Bangladesh: A study of first 14 month's daily confirmed new cases and deaths. Global Biosecurity. 2021;3(1). doi:10.31646/gbio.91

14. Slum Census and Floating Population 2014. Bangladesh Bureau of Statistics http://203.112.218.6 5:8008/PageWebMenuContent. aspx?MenuKey=423. Accessed August 15, 2021.

15. Al Noman A, Islam MdS, Sana S, et al. A review of the genome, epidemiology, clinical features, prevention, and treatment scenario of COVID-19: Bangladesh aspects. Egypt J Bronchol. 2021;15(1):8. do i:10.1186/s43168-021-00053-2

16. Rahman MM, Bhattacharjee B, Farhana Z, et al. Age-related risk factors and severity of SARS-CoV-2 infection: A systematic review and meta-analysis. $J$ Prev Med Hyg. 2021;62(2):E329-E371. doi:10.15167/24 21-4248/JPMH2021.62.2.1946

17. Khun S, Manderson L. Community Participation and Social Engagement in the Prevention and Control of Dengue Fever in Rural Cambodia. WHO Regional Office for South-East Asia; 2008. https://apps.who.int/iris/h andle/10665/170479. Accessed August 15, 2021. 